\title{
Induction of apoptotic cell death by betulin in multidrug-resistant human renal carcinoma cells
}

\author{
NAM-HUI YIM, YOUNG PIL JUNG, AEYUNG KIM, TAESOO KIM and JIN YEUL MA \\ Korean Medicine (KM)-Based Herbal Drug Development Group, Korea Institute of Oriental Medicine (KIOM), \\ Yuseong-gu, Daejeon 305-811, Republic of Korea
}

Received March 9, 2015; Accepted April 30, 2015

DOI: $10.3892 /$ or.2015.4045

\begin{abstract}
Betulin, a triterpene from the bark of various species of birch tree, has various biological effects, including antiviral, antifungal and anticancer activities. The aim of the present study was to elucidate the mechanisms underlying the apoptotic effect of betulin in RCC4 multidrug-resistant human renal carcinoma cells. To evaluate anticancer activity, we performed cell viability and caspase activity assays, a proteome profiler array and western blot analysis in RCC4 cells. Betulin significantly decreased RCC4 cell viability in a time- and concentration-dependent manner. Betulin activated caspase family proteins, including caspase-3, -7, -8 and -9, and increased the expression of apoptosis-related proteins, including PARP and Bcl-2 family members. In an apoptosis array, betulin activated the tumour necrosis factor-related apoptosis-inducing ligand (TRAIL) receptors TRAIL R1/DR4 and R2/DR5, and tumour necrosis factor receptor 1 (TNFR1), suggesting that betulin treatment leads to induction of apoptosis through both intrinsic and extrinsic apoptosis pathways in RCC4 cells. Notably, betulin significantly enhanced cytotoxicity and PARP cleavage in etoposide-treated RCC4 cells, and downregulated the expression of multidrug resistance protein 1 (MDR1). Taken together, our findings suggest that the anticancer effects of betulin involve induction of apoptosis and sensitisation of RCC4 cells, providing potentially useful information applicable to the use of betulin in renal cancer treatment.
\end{abstract}

\section{Introduction}

Renal cell carcinoma ( RCC) is the most common type of kidney cancer. RCC accounts for an estimated 3-5\% of all malignant tumours, and this figure increases annually (1). Nearly $50 \%$ of

Correspondence to: Dr Jin Yeul Ma, Korean Medicine (KM)-Based Herbal Drug development Group, Korea Institute of Oriental Medicine (KIOM), 1672 Yuseongdaero, Yuseong-gu, Daejeon 305-811, Republic of Korea

E-mail: jyma@kiom.re.kr

Key words: betulin, renal carcinoma cells, apoptosis, caspases, multidrug resistance patients suffer relapse and metastasis after curative surgical resection (2). RCC is highly resistant to radiotherapy and other formal chemotherapies (3). More recently, immunotherapy with cytokines, such as interleukin-2, interferon- $\alpha$ and interferon- $\gamma$, has become the preferred treatment for later disease phases; however, the response rate is less than $20 \%$ (4). Therefore, there is a need for an alternative systemic treatment for RCC that overcomes resistance to current anticancer drugs.

Resistance to multiple categories of chemotherapy agents, termed multidrug resistance (MDR), is a complex hurdle in cancer therapy (5). The mechanisms behind MDR are still under active investigation, yet members of the ATP binding cassette $(\mathrm{ABC})$ transporter superfamily, which often act as cellular efflux pumps for a wide range of chemotherapeutic compounds are implicated (6). Over 49 MDR genes have been described, among which the ABCB1 gene, encoding the efflux transporter P-glycoprotein (P-gp) or MDR1, is probably the most well known (7). The prognostic significance of P-gp as an indicator for failure in chemotherapy has been demonstrated in a number of clinical studies (8).

Induction of apoptosis in cancer cells is desirable, and is a novel cancer therapeutic strategy (9). Apoptosis can be induced through two major pathways: i) the extrinsic pathway, which is initiated by specific ligands, such as the Fas-ligand (Fas-L), tumour necrosis factor (TNF) and the tumour necrosis factor-related apoptosis-inducing ligand (TRAIL), which activates caspase-8; and ii) the intrinsic pathway, which is activated by intracellular signals from the mitochondria to activate caspase-9 (10-12). Caspase-3, activated by the intrinsic and extrinsic pathways, induces the cleavage of poly(ADP-ribose) polymerase (PARP), a DNA repair enzyme, ultimately leading to programmed cell death (13).

Betulin [lup-20(29)-ene-3ß,28diol] (Fig. 1A) is a triterpene compound found in plants. It is commonly isolated from the bark of various species of birch tree, including Betula pendula Roth., B. alba L. and B. pubescens Ehrh. (14), as well as from other plants, such as Pyrus pyrifolia (15) and Platycodon grandiflorum (16), by solvent extraction or purified chromatography. Betulin exhibits numerous biological effects, including antiviral activities against the human Epstein-Barr virus (EBV) (17), and antifungal activities against Epidermophyton floccosum and Microsporum spp. (18). Recently, betulin has been shown to exhibit activity against several cancer cell types, including DLD-1, PC-3, HeLa, SK-HEP-1, HepG2, A549 and 
MCF-7 cells, through induction of the mitochondrial pathway associated with apoptosis $(19,20)$. However, the cytotoxicity of betulin in RCCs and its mechanisms of action have not yet been reported.

The aim of the present study was to investigate whether betulin inhibits the growth of anticancer drug-resistant human renal cancer cells, and to define the molecular basis of this effect. In the present study, we confirmed that betulin exerts its anticancer effect in human renal cancer cells by modulating key elements of the apoptotic pathway. We also demonstrated that the cytotoxicity of betulin towards RCC4 cells is enhanced by combination with anticancer drugs, through suppression of MDR1 levels.

\section{Materials and methods}

Cell culture. Various human cancer cell lines, obtained from the Korean Cell Line Bank (KCLB; Seoul, Korea) and the American Type Culture Collection (ATCC; Rockville, MD, USA), were cultured in Dulbecco's modified Eagle's medium (DMEM) and RPMI-1640 (Lonza, Walkersville, MD, USA) with $10 \%$ fetal bovine serum (FBS; HyClone, Logan, UT, USA). All media contained $100 \mathrm{U} / \mathrm{ml}$ penicillin $\mathrm{G}$ and $100 \mu \mathrm{g} / \mathrm{ml}$ streptomycin (Gibco, Gaithersburg, MD, USA). Cells were maintained in an incubator with a humidified atmosphere of $5 \% \mathrm{CO}_{2}$ at $37^{\circ} \mathrm{C}$.

Reagents and antibodies. Betulin used in the present study and anticancer drugs including 5-fluorouracil (5-FU), etoposide and temozolomide, were purchased from Sigma-Aldrich (St. Louis, MO, USA). Dimethylsulfoxide (DMSO) and 3-(4,5-dimethylthiazol-2-yl)-2,5-diphenyltetrazolium bromide (MTT), hexamethylpararosaniline chloride (crystal violet) and necrostatin-1 (Nec-1) were also purchased from Sigma-Aldrich. General caspase inhibitor, Z-VAD-fmk, was purchased from R\&D Systems (Minneapolis, MN, USA). Cytotoxicity detection kit [lactate dehydrogenase (LDH)] was purchased from Roche Diagnostics (Mannheim, Germany). RIPA buffer for protein lysis from cells was obtained from Millipore ${ }^{\mathrm{TM}}$ (Billerica, MA, USA). Primary antibodies against caspase-3,

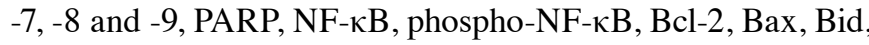
Bad, PUMA, X-linked inhibitor of apoptosis protein (XIAP), GAPDH and TBP were purchased from the Cell Signaling (Danvers, MA, USA). The primary antibodies against active caspase-3 and MDR1 were purchased from Abcam (Cambridge, UK) and GeneTex (Irvine, CA, USA), respectively.

Cell viability and cytotoxicity assays. The cell viability assay was determined by a modified MTT colorimetric assay based on the reduction of tetrazolium salt as previously described (21). The color intensity was measured as absorbance at $540 \mathrm{~nm}$ with an ELISA microplate reader (Sunrise; Tecan, Männedorf, Switzerland). To determine cytotoxicity induced by betulin, $\mathrm{LDH}$ released from the cells was evaluated with a commercial kit according to the manufacturer's instructions.

Caspase activity assay. The activation of caspases including caspase-3/7, -8 and -9 , was respectively measured using a Caspase-Glo 3/7, 8 and 9 assay kit (Promega, Madison, WI, USA) according to the manufacturer's instructions. Culture medium was used as a blank control, and luminescence was measured using an MLX Microtiter Luminometer (Dynex Technologies, Inc., Chantilly, VA, USA).

Preparation of cytosolic and nuclear extracts for $N F-\kappa B$ detection. Cytosolic and nuclear fractions were isolated from the cells using NE-PER nuclear and cytoplasmic extraction reagents (Thermo Scientific, Rockford, IL, USA) according to the manufacturer's instructions. The fractions were stored at $-80^{\circ} \mathrm{C}$ before use.

Western blot analysis. The cells treated with betulin were cultured for 12 or $24 \mathrm{~h}$ and were lysed in RIPA buffer. The lysates were centrifuged at $14,000 \mathrm{rpm}$ for $20 \mathrm{~min}$ at $4^{\circ} \mathrm{C}$ and its clear supernatant was collected. Western blot analysis was performed as previously described (21). The specific proteins were detected using a SuperSignal West Pico Chemiluminescent Substrate (Pierce, Rockford, IL, USA) and an ImageQuant LAS 4000 Mini (GE Healthcare, Piscataway, NJ, USA). Band intensities were determined using ImageJ software (National Institute of Health, USA).

Apoptosis array. Human Apoptosis Proteome Profiler ${ }^{\mathrm{TM}}$ array (R\&D Systems) was composed of a nitrocellulose membrane duplicate spot of 35 apoptosis-related proteins. The cells $\left(1 \times 10^{7}\right.$ cells $\left./ \mathrm{ml}\right)$ were harvested, and $250 \mu \mathrm{g}$ of total protein was used for each array. All analyses were performed according to the manufacturer's instructions. The membranes were incubated with horseradish peroxidase-conjugated followed by chemiluminescent detection reagent.

Statistical analysis. Data are presented as means \pm standard deviation (SD). The statistical significance was analyzed by the two-tailed Student's t-test, and a P-value of $<0.05$ was considered to indicate a statistically significant result.

\section{Results}

Betulin decreases the viability of RCC4 multidrug-resistant human renal carcinoma cells in a time-and concentrationdependent manner. Four human cancer cell lines [RCC4 (kidney), AGS (stomach), HeLa (cervical) and SK-Hep-1 (liver)] were treated with $0,6.25,12.5,25$ or $50 \mu \mathrm{M}$ betulin for $48 \mathrm{~h}$, and cell viability was assessed using the MTT assay. Among the cell lines, the viability of RCC4 cells was potently inhibited by treatment with betulin (Fig. 1B). Betulin inhibited the viability of the RCC4 cells with $\mathrm{IC}_{50}$ values of 23.1 and $14.8 \mu \mathrm{M}$ after 24 and $48 \mathrm{~h}$, respectively (Fig. 1C). In addition, LDH release was observed after a $24-\mathrm{h}$ betulin treatment, and this was significantly increased at betulin doses exceeding $12.5 \mu \mathrm{M}$ (Fig. 1D). Accordingly, 10 and $25 \mu \mathrm{M}$ betulin were used in further studies to identify the mechanisms underlying the effect on RCC4 cell viability.

Betulin induces cancer cell death by activating the caspase-mediated apoptosis pathway in RCC4 cells. To determine whether betulin-induced cytotoxicity is related to apoptosis, the expression of pro-apoptotic and anti-apoptotic proteins in RCC4 cells was assessed by western blotting. The expression levels of proteins associated with apoptosis 
A

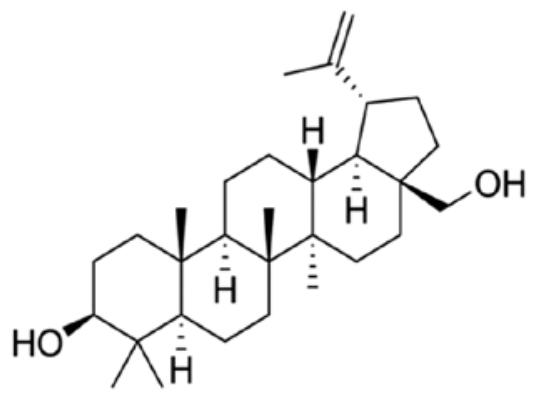

C

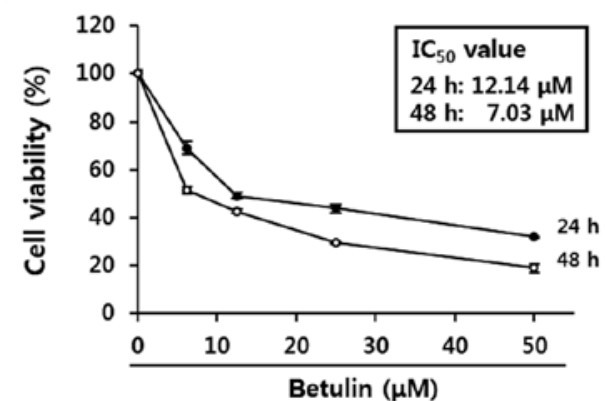

B $\square 0 \mu \mathrm{M} \square 6.25 \mu \mathrm{M} \quad \square 12.5 \mu \mathrm{M} \quad \square 25 \mu \mathrm{M} \quad \square 50 \mu \mathrm{M}$

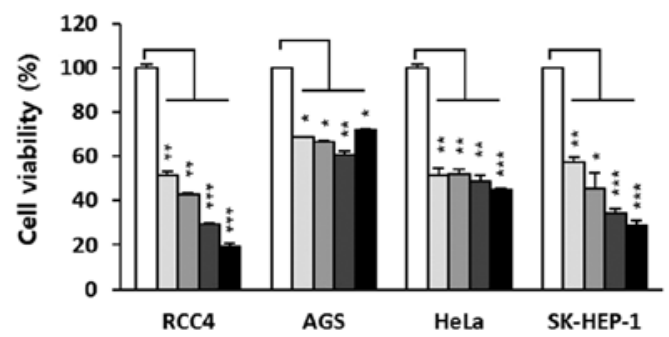

D

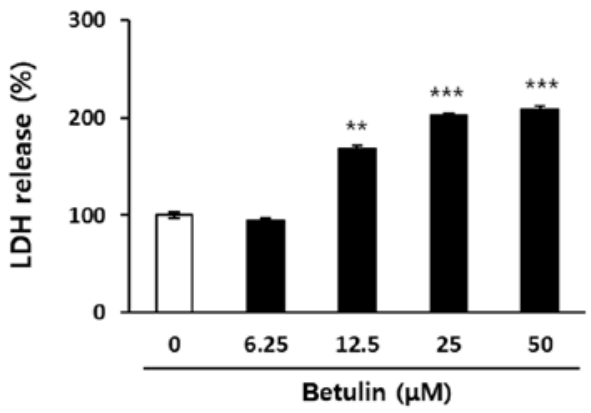

Figure 1. Inhibitory effect of betulin on the proliferation of human cancer cells. Cell viability was determined using the MTT assay. (A) Chemical structure of betulin. (B) Inhibition of viability by betulin in several human cancer cell lines. Cancer cells were treated with $0,6.25,12.5,25$ or $50 \mu \mathrm{M}$ betulin for $48 \mathrm{~h}$. (C) $\mathrm{IC}_{50}$ values of betulin in the RCC4 cells. Cells were treated with $0,1.56,3.12,6.25,12.5,25$ or $50 \mu \mathrm{M}$ betulin for 24 or $48 \mathrm{~h}$. (D) LDH release in response to betulin treatment of the RCC4 cells. Cells were treated with $0,6.25,12.5,25$ or $50 \mu \mathrm{M}$ betulin for $24 \mathrm{~h}$, and the release of LDH was determined using an LDH detection kit. Data are presented as the means $\pm \mathrm{SD}$ of two independent triplicates. ${ }^{*} \mathrm{P}<0.05,{ }^{* *} \mathrm{P}<0.01$ and ${ }^{* * * *} \mathrm{P}<0.001$ indicate statistical significance, compared to an untreated control. LDH, lactate dehydrogenase.

A

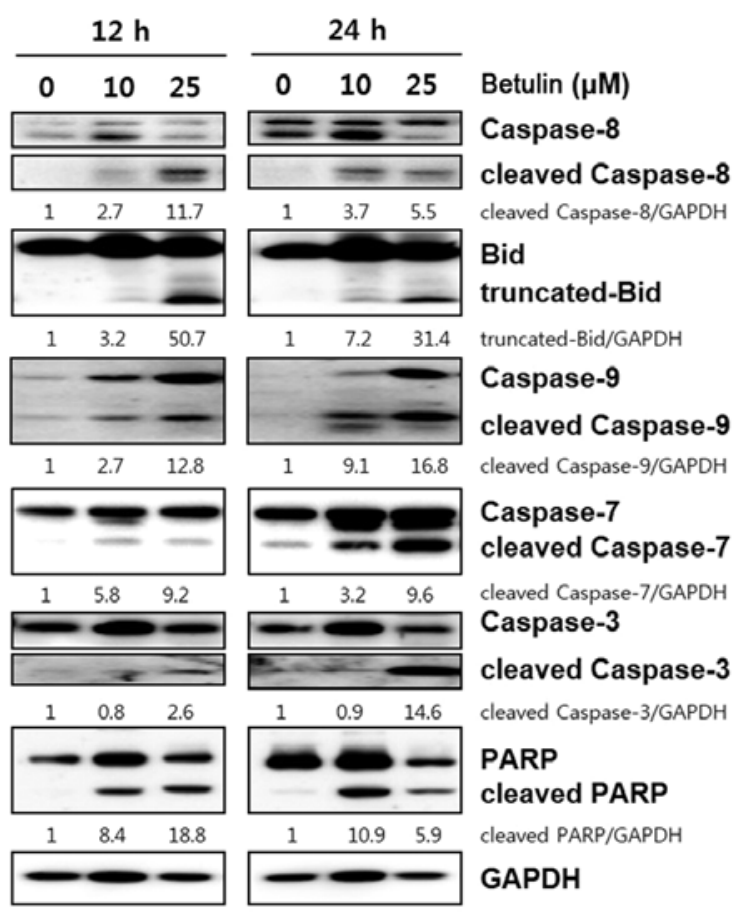

B

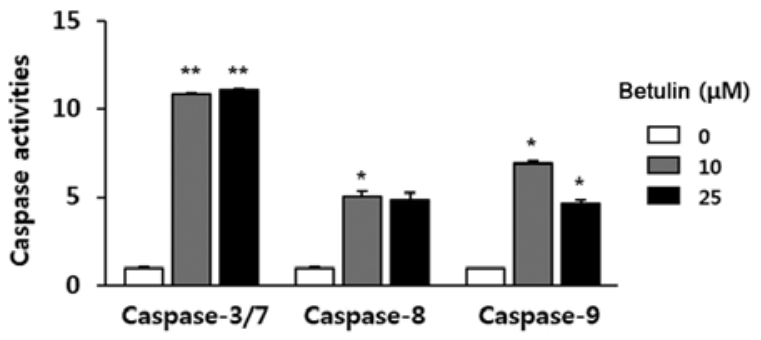

C

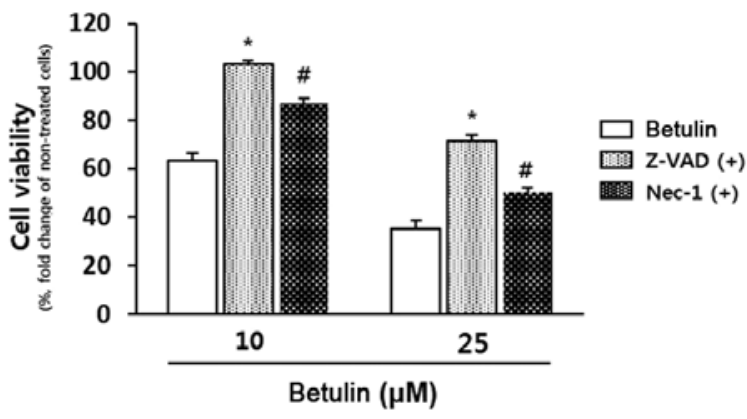

Figure 2. Verification of caspase-dependent apoptosis induced by betulin in RCC4 cells. (A) Effect of betulin on caspase protein expression. Cells were exposed to 10 and $25 \mu \mathrm{M}$ betulin for 12 and $24 \mathrm{~h}$. Band intensity compared to untreated cells was calculated using ImageJ after neutralization relative to GAPDH expression. Data represent two independent experiments. (B) Relative luminescence indicating dose-dependent activation of caspase-3/7, -8 and -9 induced by a 24 -h treatment with betulin. Data represent two independent triplicates. ${ }^{*} \mathrm{P}<0.05$ and ${ }^{* *} \mathrm{P}<0.01$ indicate statistical significance, compared to an untreated control. (C) Assessment of the apoptotic effect of a 24-h betulin treatment using a caspase inhibitor. Cells were respectively exposed to Z-VAD-fmk, a general caspase inhibitor and Nec-1, a necroptosis inhibitor, for $30 \mathrm{~min}$ before addition of betulin $(10$ and $25 \mu \mathrm{M})$. After $24 \mathrm{~h}$, cell viability was determined using the MTT assay. Data are presented as means \pm SD. P-values indicate statistical significance, compared to betulin treatment ( $\mathrm{P}<0.05$, Z-VAD-fmk; ${ }^{\#} \mathrm{P}<0.05$, Nec-1). Nec-1, necrostatin-1. 
A
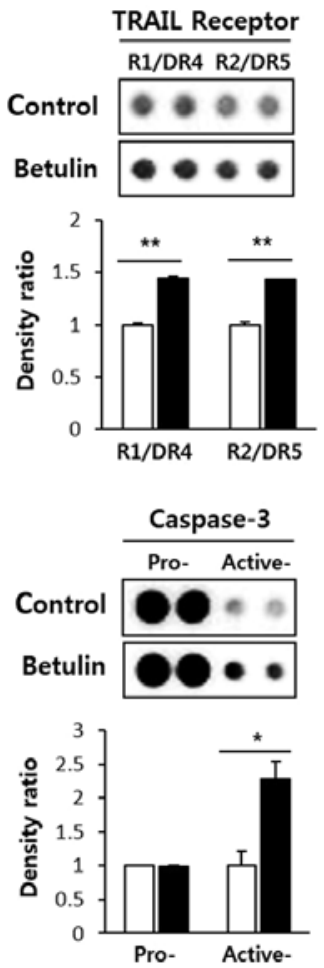

TNF R1
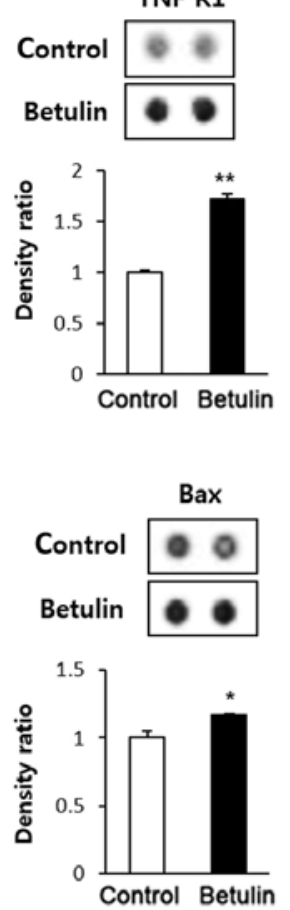

B
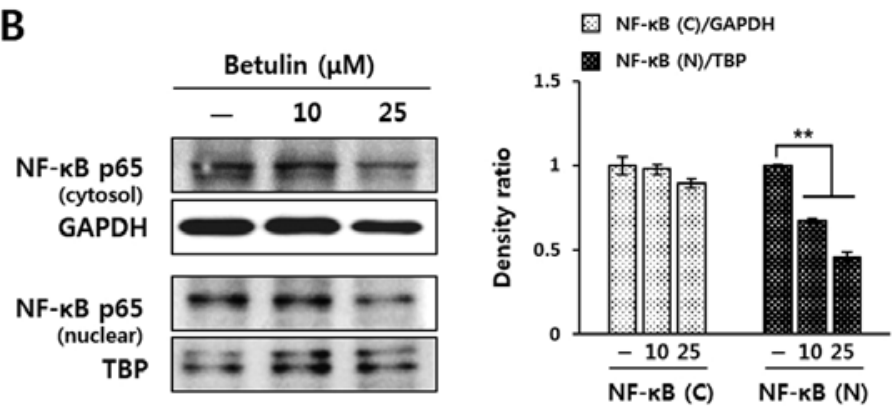

C

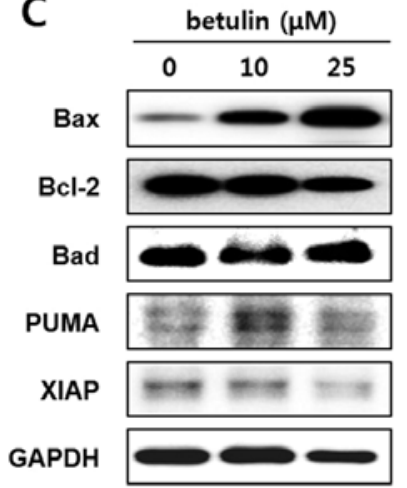

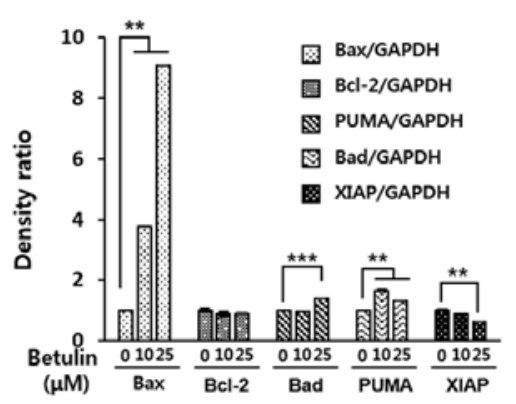

Figure 3. Effect of betulin on apoptosis-related proteins in RCC4 cells. (A) Analysis of the proteome profiler array of betulin. Cells were exposed to $10 \mu \mathrm{M}$ betulin for $24 \mathrm{~h}$ and subjected to a proteome profiler array, according to the manufacturer's instructions. The levels of the indicated proteins (Bax, caspase-3, TRAIL R1/DR4 and R2/DR5, and TNFR1), as shown in the histograms, were quantified using ImageJ. " $\mathrm{P}<0.05$ and ${ }^{* *} \mathrm{P}<0.01$ indicate statistical significance, compared to an untreated control. (B) Inhibition of betulin induced nuclear translocation of NF- $\mathrm{kB}$. After a 24-h treatment of RCC4 cells with betulin, the levels of NF-kB (p65) in the cytosol and nucleus were determined by western blot analysis and quantified using ImageJ. TBP was used as a nuclear loading control. Data represent two independent experiments. ${ }^{*} \mathrm{P}<0.05$, and ${ }^{* *} \mathrm{P}<0.01$ indicate statistical significance, compared to an untreated control. (C) Betulininduced regulation of Bcl-2 family protein expression. Cells were treated with betulin for $24 \mathrm{~h}$, and the expression levels of Bax, Bcl-2, Bad, PUMA and XIAP were assessed by western blot analysis. Protein levels were quantified using ImageJ and normalised relative to GAPDH expression. ${ }^{* *} \mathrm{P}<0.01$ and ${ }^{* * * *} \mathrm{P}<0.001$ indicate statistical significance, compared to an untreated control.

were clearly influenced by betulin treatment (Fig. 2A). Pro-caspase- $3,-7,-8$ and -9 were cleaved to their active forms after exposure to 10 and $25 \mu \mathrm{M}$ betulin for $12 \mathrm{~h}$ in RCC4 cells. Betulin also induced truncation of Bid and cleavage of PARP in a time- and dose-dependent manner. Most caspases were strongly activated by a $24-\mathrm{h}$ betulin treatment. Particularly at a $25 \mu \mathrm{M}$ dose, all caspases were induced $>6$-fold, compared to the levels detected in the untreated RCC4 cells. In addition, levels of truncated Bid (t-Bid) and cleaved PARP increased by $12-$ and 6 -fold, respectively. To confirm that apoptosis induced by betulin requires caspase activation, a caspase activity assay was performed in the RCC4 cells (Fig. 2B). Betulin at 10 and $25 \mu \mathrm{M}$ doses significantly increased the activities of caspase-3/7, -8 and -9 at $24 \mathrm{~h}$. Betulin at $10 \mu \mathrm{M}$ markedly increased the activities of caspase-3/7, -8 and -9 , $\sim 10-, 5$ - and 7-fold compared to the non-treated cells, respectively. As shown in Fig. 3C, in the inhibitor study, pre-incubation with Z-VAD-fmk, a broad-spectrum caspase inhibitor, for $30 \mathrm{~min}$ significantly blocked betulin-induced cell death at $10 \mu \mathrm{M}$ betulin. Pre-incubation with Nec-1, a necroptosis inhibitor, blocked betulin-induced cell death; however, the cell death was not completely blocked at 10 and $25 \mu \mathrm{M}$ betulin compared to the effects of Z-VAD-fmk. These data support the hypothesis that the anticancer effects of betulin in RCC4 cells are related to apoptotic cell death resulting from activation of caspases.
Betulin treatment leads to the expression of apoptosis-related proteins in RCC4 cells. The betulin-induced expression of apoptosis-related proteins was calculated using proteome array panels (Fig. 3A). After a 24-h treatment of RCC4 cells with $10 \mu \mathrm{M}$ betulin, the protein levels related to apoptosis, such as Bax, active caspase-3, TNF-related apoptosis-inducing ligand (TRAIL) receptor 1/DR4 and 2/DR5, and tumour necrosis factor receptor 1 (TNF R1) were upregulated. Bax and active caspase-3 levels were significantly upregulated, with active caspase-3 levels increasing $>2$-fold compared to the untreated cells. Betulin increased the levels of TRAIL R1/DR4 and R2/DR 5 by 43 and $42 \%$, respectively. Betulin also induced upregulation of TNFR1 protein expression by $72 \%$. The NF- $\mathrm{BB}$ pathway is closely associated with the expression of TNFR1. Therefore, we determined the effect of betulin on the nuclear translocation of p65 in the RCC4 cells. As shown in Fig. 3B, the nuclear translocation of p65 was significantly suppressed by betulin in a concentration-dependent manner for $24 \mathrm{~h}$. To confirm that betulin-induced apoptosis is associated with the mitochondrial-mediated pathway, the levels of Bcl-2 family proteins including Bcl-2, Bax, Bad and PUMA and XIAP, were estimated by western blot analysis (Fig. 3C). The results demonstrated that the betulin increased the expression of pro-apoptotic proteins. Specifically, a significant increase in Bax and PUMA expression was observed in response to a $10 \mu \mathrm{M}$ dose of betulin for $24 \mathrm{~h}$. Conversely, 
A

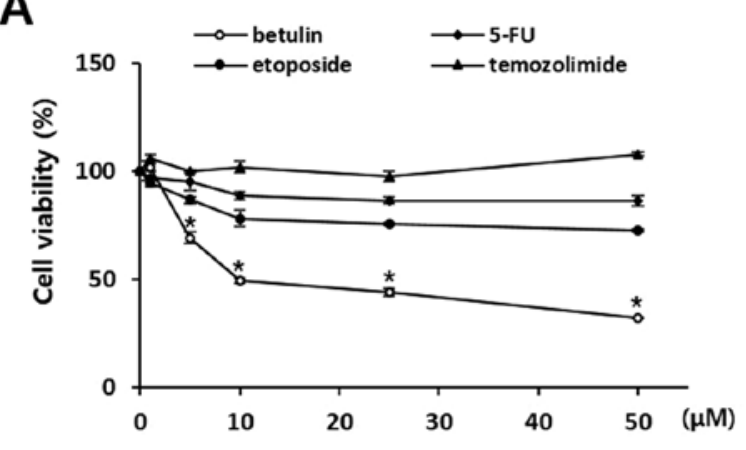

B

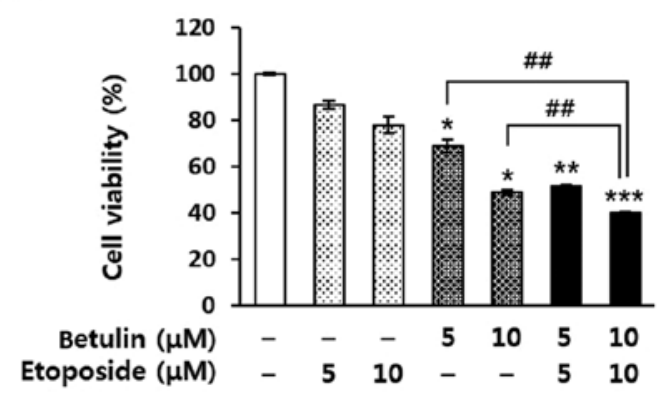

C
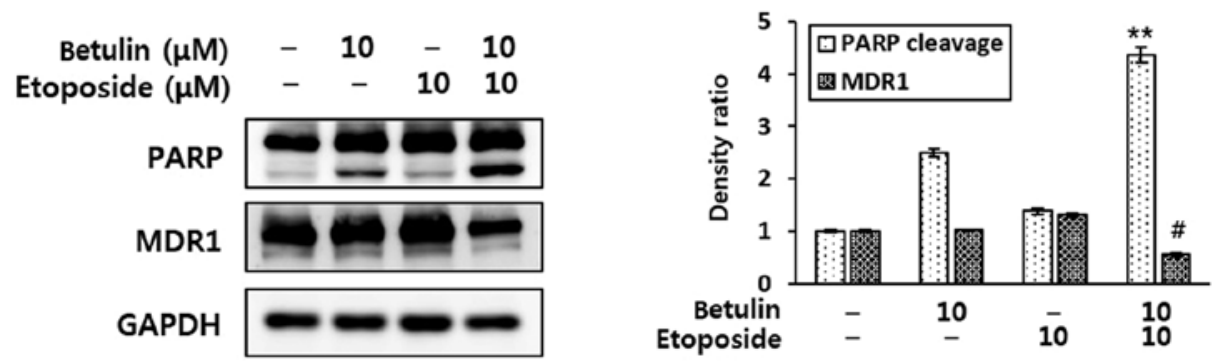

Figure 4. The combined effect of the co-treatment of betulin and anticancer agents in RCC4 cells. (A) Enhancement of anticancer agent-induced cell death by betulin in the RCC4 cells. Cells were treated with various concentrations (1, 5, 10, 25 and $50 \mu \mathrm{M})$ of betulin or anticancer drugs (5-FU, etoposide and temozolimide). After $24 \mathrm{~h}$, cell viability was determined using an MTT assay. Data are presented as means \pm SD. * $\mathrm{P}<0.05$ indicates statistical significance, compared to the untreated control. (B) Evaluation of the combined effect of betulin and etoposide on the cell growth of RCC4 cells. After a 24-h treatment of RCC4 cells with betulin $(5$ and $10 \mu \mathrm{M})$ and/or etoposide $(5$ and $10 \mu \mathrm{M})$, an MTT assay was performed. ${ }^{*} \mathrm{P}<0.05,{ }^{* *} \mathrm{P}<0.01$ and ${ }^{* * * *} \mathrm{P}<0.01$ indicate statistical significance, compared to an untreated control. ${ }^{\# \#} \mathrm{P}<0.01$ indicates statistical significance, compared to betulin alone. (C) Enhancement of the anticancer effect by combined treatment with betulin and etoposide. Cells were treated with betulin $(10 \mu \mathrm{M})$ and/or etoposide (10 $\mu \mathrm{M})$ for $24 \mathrm{~h}$, and the expression levels of PARP and MDR1 were determined by western blot analysis. Protein levels were normalised relative to GAPDH expression and quantified using ImageJ. ${ }^{* *} \mathrm{P}<0.01$ indicates statistical significance of PARP cleavage, compared to etoposide treatment alone and ${ }^{\#} \mathrm{P}<0.01$ indicates statistical significance of MDR1 expression compared to etoposide treatment alone.

the expression levels of anti-apoptotic proteins, such as Bcl-2 and XIAP, were decreased markedly following treatment with $10 \mu \mathrm{M}$ betulin.

Betulin enhances the sensitivity of RCC4 cells to anticancer drugs. We hypothesised that betulin sensitises renal cancer cells to anticancer drugs. To test this, we treated cells with betulin in combination with anticancer drugs, including 5-FU, etoposide and temozolomide. 5-FU, etoposide and temozolomide weakly inhibited the growth of the RCC4 cells after 24 h by $13.54,24.38$ and $2.43 \%$, respectively, compared to the control condition, whereas the addition of $25 \mu \mathrm{M}$ betulin resulted in inhibition of cell growth by up to $56.12 \%$ (Fig. 4A). In addition, by co-treating cells with etoposide in the presence of betulin, the cytotoxicity of the RCC4 cells was significantly increased. The cytotoxicity induced by co-treatment with $5 \mu \mathrm{M}$ etoposide and $5 \mu \mathrm{M}$ betulin was almost equal to that of $10 \mu \mathrm{M}$ betulin alone (Fig. 4B). To confirm the synergistic effect of betulin and etoposide on cancer cell death, the levels of cleaved PARP and MDR1 were assessed in RCC4 cells using western blot analysis. As shown in Fig. 4C, co-treatment with $10 \mu \mathrm{M}$ etoposide and $10 \mu \mathrm{M}$ betulin increased the level of cleaved PARP >2- and 3-fold, compared to betulin and etoposide treatment alone, respectively. In the case of MDR1, elevated expression of MDR1 was observed in the RCC4 cells, and this was decreased $\sim 2$-fold by co-treatment with $10 \mu \mathrm{M}$ betulin and $10 \mu \mathrm{M}$ etoposide. However, treatment with betulin or etoposide alone did not affect MDR1 expression.

\section{Discussion}

The induction of apoptosis in cancer cells by natural compounds is a key goal for cancer prevention and therapy. Betulin is a pharmacologically active triterpene that is naturally occurring in birch bark. It is used in its extracted form or as a base for chemical modification to compounds such as betulinic acid (22). Previous studies have reported that betulin has an anticancer effect in human lung, cervical and liver cancer cells (23). Betulin has also been shown to protect hepatoma cells from damage by ethanol-induced liver stellate or cadmium-induced apoptosis, via a mechanism involving inhibition of reactive oxygen species (ROS) production or apoptosis induction $(24,25)$. In HepG 2 cells, betulin was found to induce apoptotic cell death through the intrinsic apoptotic pathway that includes activation of caspase-9 and -3 (23). Caspase is a key mediator of apoptosis that is activated via endoplasmic reticulum stress, extracellular stimuli and mitochondrial damage (26). The activation of caspase- 8 is initiated by the stimulation of cell-surface death receptors, such as Fas, TNF and TRAIL. This leads to activation of caspase- 3 or -7 , or modulation of the mitochondrial pathway via truncation of Bid (27). Conversely, caspase-9 is activated 
by cytochrome $c$ released from the mitochondria, which in turn, leads to the activation of effector caspases, such as caspase-3, -6 and -7. Activated caspase-3 induces cleavage of PARP, a DNA repair enzyme, and ultimately, apoptosis (28). The present study revealed that betulin treatment inhibited the viability of human renal cancer cells and increased the activity of caspases, including caspase-3, -7, -8 and -9. Furthermore, our data indicated that betulin regulates mitochondrial signalling pathways associated with apoptosis, including the Bcl-2 family and XIAP pathways, which suggests that sensitisation of cancer cells by betulin to apoptosis is caspase-9-dependent. Notably, in the present study, betulin significantly increased the levels of TRAIL R1/DR4 and R2/DR5, and TNFR1 in an apoptosis array. TRAIL induces apoptosis in a variety of transformed or tumour cells, but not in normal cells; however, many cancer cells are resistant to TRAIL (27). Binding of TRAIL to the TRAIL R1/DR4 and R2/DR5 receptors results in trimerisation to form a death-inducing signalling complex (DISC). DISC recruits the adapter protein FADD and caspase-8, leading to activation of intact caspases and cleavage of PARP (29). Therefore, increased expression of the TRAIL death receptors could play an important role in the sensitisation of cancer cells to TRAIL-associated apoptosis following proteasome inhibition. TNFR1 induces the activation of NF- $\kappa \mathrm{B}$ and plays a role in caspase- 8 activation by controlling the receptor interacting protein-1 (RIP1) (30). NF- $\kappa \mathrm{B}$ is an apoptosis regulator, and its inhibition results in apoptosis in a variety of cell types found to be initially resistant to TNF- $\alpha$ induced apoptosis $(31,32)$. Furthermore, in cancer therapy, suppression of $\mathrm{NF}-\kappa \mathrm{B}$ translocation can increase the effectiveness of cancer therapy (33). Hence, our data demonstrated that stimulation of TRAIL receptors and TNFR1 by betulin results in activation of caspase -8 and inhibition of NF- $\kappa$ B signalling. Therefore, we suggest that betulin treatment leads to induction of apoptosis through both the intrinsic and extrinsic pathways in RCC4 cells.

Additionally, we demonstrated that betulin inhibits cell viability by inducing caspase-mediated apoptosis in RCC4 human renal carcinoma cells shown to be resistant to anticancer drugs, such as 5-FU, temozolomide and etoposide. Among them, etoposide is a topoisomerase inhibitor that disrupts the repair of DNA damage. DNA-damaging drugs are highly effective anticancer drugs that are in current clinical use; however, side-effects, including vomiting, have been reported in several studies (34). RCCs are the most common malignant tumours found in the adult kidney, and unlike other malignancies, they are generally resistant to conventional therapies. Therapeutic resistance in RCCs occurs as a result of genetic changes that confer tumourigenic potential and survival advantages during chemotherapy $(35,36)$. Most of the established resistance-modifying agents (RMA) are excessively toxic at the required doses. The search for P-gp inhibitors among libraries of natural products may be more promising, as many natural products and phytotherapeutics are appreciated for their low incidence and severity of side-effects and good tolerability (5). Previous studies have revealed that the first intron of the human MDR1 gene binds to NF- $\kappa \mathrm{B}$ complexes (37). In the present study, betulin alone or in combination with etoposide, significantly increased the protein level of cleaved PARP, while etoposide alone did not affect cleavage of PARP. Furthermore, the combination of betulin and etoposide significantly suppressed MDR1 expression, whereas either drug alone did not. Betulin inhibited the translocation of $N F-\kappa B$, yet failed to affect the expression of MDR1. Thus, we suggest that betulin and anticancer drugs synergistically enhance toxicity in multidrug-resistant human renal carcinoma cells. Further research is necessary to identify the sensitising molecular mechanism and in vivo therapeutic benefits of combination therapy involving betulin and anticancer drugs.

In conclusion, we demonstrated that betulin induced apoptosis in RCC4 cells via activation of death-inducing receptors, including TRAIL receptors and TNFR1, and regulation of anti-apoptotic or pro-apoptotic proteins. Furthermore, the combination of betulin and an anticancer agent synergistically inhibited PARP expression and upregulated MDR1 expression in RCC4 cells. Therefore, we suggest that betulin is a promising candidate chemopreventive and chemotherapeutic agent for multidrug-resistant human renal cancer.

\section{Acknowledgements}

The present study was supported by a grant (K14050) awarded to the Korean Institute of Oriental Medicine by the Ministry of Education, Science and Technology (MEST), Republic of Korea.

\section{References}

1. Siegel R, Naishadham D and Jemal A: Cancer statistics, 2012. CA Cancer J Clin 62: 10-29, 2012.

2. Morais C, Pat B, Gobe G, Johnson DW and Healy H: Pyrrolidine dithiocarbamate exerts anti-proliferative and proapoptotic effects in renal cell carcinoma cell lines. Nephrol Dial Transplant 21: 3377-3388, 2006.

3. Hong MH1, Kim HS, Kim C, Ahn JR, Chon HJ, Shin SJ, Ahn JB, Chung HC and Rha SY: Treatment outcomes of sunitinib treatment in advanced renal cell carcinoma patients: A single cancer center experience in Korea. Cancer Res Treat 41: 67-72, 2009.

4. McDermott DF: Immunotherapy of metastatic renal cell carcinoma. Cancer 115 (Suppl 10): S2298-S2305, 2009.

5. Zhu L, Zhao L, Wang H, Wang Y, Pan D, Yao J, Li Z, Wu G and Guo Q: Oroxylin A reverses P-glycoprotein-mediated multidrug resistance of MCF7/ADR cells by G2/M arrest. Toxicol Lett 219: 107-115, 2013.

6. Benabbou N, Mirshahi P, Cadillon M, Soria J, Therwath A and Mirshahi M: Hospicells promote upregulation of the ATP-binding cassette genes by insulin-like growth factor-I via the JAK2/STAT3 signaling pathway in an ovarian cancer cell line. Int J Oncol 43: 685-694, 2013.

7. Harris AL and Hochhauser D: Mechanisms of multidrug resistance in cancer treatment. Acta Oncol 31: 205-213, 1992.

8. Kimura Y, Morita SY, Matsuo M and Ueda K: Mechanism of multidrug recognition by MDR1/ABCB1. Cancer Sci 98: 1303-1310, 2007.

9. Kopnin BP: Targets of oncogenes and tumor suppressors: Key for understanding basic mechanisms of carcinogenesis. Biochemistry. Biokhimiia 65: 2-27, 2000.

10. Lowe SW and Lin AW: Apoptosis in cancer. Carcinogenesis 21: 485-495, 2000.

11. Desagher S and Martinou JC: Mitochondria as the central control point of apoptosis. Trends Cell Biol 10: 369-377, 2000.

12. Jin Z and El-Deiry WS: Overview of cell death signaling pathways. Cancer Biol Ther 4: 139-163, 2005.

13. D'Amours D, Desnoyers S, D'Silva I and Poirier GG: Poly(ADPribosyl)ation reactions in the regulation of nuclear functions. Biochem J 342: 249-268, 1999.

14. Flekhter OB, Medvedeva NI, Tolstikov GA, Galin FZ, Iunusov MS, Huong NT, Le VT, Svinova OV, Boreko EI, Titov LP, et al: Synthesis of olean-18(19)-ene derivatives from betulin. Bioorg Khim 35: 253-259, 2009 (In Russian). 
15. Yoo JH and Yang KS: Lupane triterpenoids from Pyrus pyrifolia. Nat Prod Sci 18: 13-15, 2012.

16. Hwang CR, Oh SH, Kim HY, Lee SH, Hwang, IG, Shin YS, Lee JS and Jeong HS: Chemical composition and antioxidant activity of Deoduk (Codonopsis lanceolate) and Doragi (Platycodon grandiflorum) according to temperature. J Korean Soc Food Sci Nutr 40: 798-803, 2011.

17. Akihisa T, Takamine Y, Yoshizumi K, Tokuda H, Kimura Y, Ukiya M, Nakahara T, Yokochi T, Ichiishi E and Nishino H: Microbial transformations of two lupane-type triterpenes and anti-tumor-promoting effects of the transformation products. J Nat Prod 65: 278-282, 2002.

18. Machado KE, Cechinel Filho V, Cruz RC, Meyre-Silva C and Cruz AB: Antifungal activity of Eugenia umbelliflora against dermatophytes. Nat Prod Commun 4: 1181-1184, 2009.

19. Pyo JS, Roh SH, Kim DK, Lee JG, Lee YY, Hong SS, Kwon SW and Park JH: Anti-cancer effect of Betulin on a human lung cancer cell line: A pharmacoproteomic approach using 2 D SDS PAGE coupled with nano-HPLC tandem mass spectrometry. Planta Med 75: 127-131, 2009.

20. Li Y, He K, Huang Y, Zheng D, Gao C, Cui L and Jin YH: Betulin induces mitochondrial cy tochrome $c$ release associated apoptosis in human cancer cells. Mol Carcinog 49: 630-640, 2010.

21. Yim NH, Cho WK, Lee JH, Jung YP, Yang HJ and Ma JY: HRT, herbal formula, induces $\mathrm{G}_{2} / \mathrm{M}$ cell cycle arrest and apoptosis via suppressing Akt signaling pathway in human colon cancer cells. eCAM 2012: 871893, 2012. doi: 10.1155/2012/871893.

22. Kvasnica M, Sarek J, Klinotova E, Dzubak P and Hajduch M Synthesis of phthalates of betulinic acid and betulin with cytotoxic activity. Bioorg Med Chem 13: 3447-3454, 2005.

23. Li Y, Shen JT, Gao C, Li Q and Jin Y: Caspase-9 activation, critical for betulin-induced apoptosis of human hepatoma cells. Chem Res Chin Univ 26: 792-797, 2010.

24. Szuster-Ciesielska A, Plewka K, Daniluk J and KandeferSzerszeń M: Betulin and betulinic acid attenuate ethanol-induced liver stellate cell activation by inhibiting reactive oxygen species (ROS), cytokine (TNF- $\alpha$, TGF- $\beta$ ) production and by influencing intracellular signaling. Toxicology 280: 152-163, 2011.
25. Oh SH, Choi JE and Lim SC: Protection of betulin against cadmium-induced apoptosis in hepatoma cells. Toxicology 220: $1-12,2006$

26. Nuñez G, Benedict MA, Hu Y and Inohara N: Caspases: The proteases of the apoptotic pathway. Oncogene 17: 3237-3245, 1998

27. Wu GS: TRAIL as a target in anti-cancer therapy. Cancer Lett 285: 1-5, 2009.

28. Green DR: Apoptotic pathways: Paper wraps stone blunts scissors. Cell 102: 1-4, 2000.

29. Humphreys RC and Halpern W: Trail receptors: Targets for cancer therapy. Adv Exp Med Biol 615: 127-158, 2008.

30. Wajant $\mathrm{H}$ : Increasing complexity in TNFR1 signaling. FEBS J 278: 861, 2011.

31. Beg AA and Baltimore D: An essential role for NF-kappaB in preventing TNF-alpha-induced cell death. Science 274: 782-784, 1996.

32. Van Antwerp DJ, Martin SJ, Kafri T, Green DR and Verma IM: Suppression of TNF-alpha-induced apoptosis by NF-kappaB. Science 274: 787-789, 1996.

33. Van Waes C: Nuclear factor-kappaB in development, prevention, and therapy of cancer. Clin Cancer Res 13: 1076-1082, 2007.

34. Moriarty TJ, Dupuis S and Autexier C: Rapid upregulation of telomerase activity in human leukemia HL-60 cells treated with clinical doses of the DNA-damaging drug etoposide. Leukemia 16: 1112-1120, 2002.

35. Thompson Coon JS, Liu Z, Hoyle M, Rogers G, Green C, Moxham T, Welch K and Stein K: Sunitinib and bevacizumab for first-line treatment of metastatic renal cell carcinoma: A systematic review and indirect comparison of clinical effectiveness. $\mathrm{Br}$ J Cancer 101: 238-243, 2009.

36. Porta C,Paglino C,Imarisio I, Ganini C and Pedrazzoli P: Immunological effects of multikinase inhibitors for kidney cancer: A clue for integration with cellular therapies? J Cancer 2: 333-338, 2011.

37. Kaewpiboon C, Srisuttee R, Malilas W, Moon J, Kaowinn S, Cho IR, Johnston RN, Assavalapsakul W and Chung YH: Extract of Bryophyllum laetivirens reverses etoposide resistance in human lung A549 cancer cells by downregulation of NF- $\mathrm{KB}$. Oncol Rep 31: 161-168, 2014. 